[Special Issue on Research and Social Justice]

\title{
The Value of Mixed Methods Designs to Social Justice Research in Counseling and Psychology
}

\author{
Joseph G. Ponterotto
}

Fordham University at Lincoln Center

\author{
Jaya T. Mathew \\ University of Wisconsin \\ Brigid Raughley \\ Fordham University at Lincoln Center
}

\begin{abstract}
This article highlights the potential value of mixed methods designs for social justice research in counseling, psychology, and related human services professions. Though representing only a small minority of research designs used in these fields, mixed methods approaches are gaining in popularity. A rationale for the use of mixed methods research in the human services generally, and multicultural/social justice counseling specifically, is presented. Various mixed methods designs are reviewed, examples of published mixed methods multicultural research are highlighted, and a flow diagram to determine whether or not to incorporate a mixed method design for a particular study is put forth. Limitations of mixed methods designs are also acknowledged.
\end{abstract}

Keywords: mixed methods, social justice, multicultural research

\section{Introduction}

Mixed methods research designs are gaining popularity among counseling and human service researchers in all specialty areas (Kohn-Wood \& Diem, 2012; Wisdom, Cavaleri, Onwuegbuzie \& Green, 2012). Conducting well-integrated mixed methods research requires high levels of competence in philosophy of science, research ethics, quantitative research methods, and qualitative inquiry approaches (Badiee, Wang, \& Creswell, 2012; Bryman, 2007; Clarke, 2009; Leech \& Onwuegbuzie, 2010; National Institutes of Health, 
2011). With regard to multicultural and social justice research, these competencies must be embedded in an over-arching framework of multicultural awareness, insight, and competencies as well as a social justice perspective (Ponterotto \& Grieger, 2008).

This article attempts to advance the status of human service research by promoting the use of expanded methodological paradigms within social justice frameworks. The article begins by defining key concepts used throughout the article so that the current authors' frame of reference is understood. Next we examine the long-standing challenges to conducting mixed methods research and we note the increasing acceptance of and use of these designs in the last decade. The third section of the article highlights the potential benefits of mixed methods designs to human services research generally, and social justice-oriented research specifically. Next we review the varieties of mixed methods designs and present a limited international review of mixed methods studies. The article closes with a specific guide and flow-chart model to help counseling and human services researchers decide whether to adopt a mixed method design for a particular study. Finally, some limitations of mixed methods designs are highlighted.

\section{Defining Mixed Methods, Research Paradigms, Multiculturalism, and Social Justice Research}

For our present discussion, mixed methods research is defined as "the class of research where the researcher mixes or combines quantitative and qualitative research techniques, methods, approaches, concepts or language into a single study" (Johnson \& Onwuegbuzie, 2004, p. 17). A mixed methods study can be distinguished from a mixed methods research program wherein a researcher may rotate separate quantitative and qualitative studies over time as the research program progresses (see Plano Clark \& Wang, 2010). It is important to note that mixed methods designs integrate not only specific quantitative and qualitative procedures, but also variant underlying research paradigms (worldviews) and philosophy of science parameters (see Creswell \& Plano Clark, 2007; Plano Clark \& Wang, 2010). Research paradigms are defined below, and philosophy of science parameters will be discussed later in the article within the context of mixed methods designs.

A paradigm can be defined as a "set of interrelated assumptions about the social world which provides a philosophical and conceptual framework for the organized study of that world" (Filstead, 1979, p. 34). Research paradigms that have guided psychological and sociological research over the past five centuries include positivism (Descartes, 1637/1968; Locke, 1689/1956; Mill, 1843/1906), postpositivism (Popper, 1968); constructivism (or interpretivism) (Dilthey, 1894/1977; Kant, 1881/1966), and criticalideological positions (Kincheloe \& McLaren, 2000) (see reviews in Guba \& Lincoln, 1994; Pearce, 2012; Ponterotto, 2005b).

Given that mixed methods researchers often draw on multiple research paradigms within the same study, it is important to define each briefly. Positivism emphasizes the hypothetico-deductive methods borrowed from the "hard" sciences (math, physics, chemistry), and prioritizes a single, apprehendable (measurable) reality, theory verification, hypothesis testing, researcher objectivity and dualism (researcher remains 
separate from the research participants), and quantitative analytic methods. Postpositivism also adheres to hypothetico-deductive scientific principles while acknowledging a single reality that can only be approximated, thus espousing theory falsification over theory verification; and noting that for topics in psychology (e.g., emotions, thoughts) quasi experimental designs are more realistic than true experimental designs.

In marked contrast to the scientific paradigm sisters of positivism and postpositivism, constructivism espouses the social construction (in the minds and worldviews of participants) of phenomena and multiple, apprehendable and equally valid realities. Furthermore, awareness and knowledge is embedded within the participant and only accessed by and co-constructed with the researcher through dialogic encounters characterized by close proximity and prolonged engagement (dualism is abandoned). Constructivists eschew numbers and quantification as the only valid source of data, relying instead on the experiences of participants accessed through words, stories, and images.

Finally, the critical-ideological paradigm acknowledges an overarching reality shaped by social and political forces and embedded in a historic (e.g., in the U.S.) power imbalance and subjugation politically, socially, and economically of less-empowered societal groups. Anchoring this paradigm is the position that "an emancipatory principle drives such research, which is committed to engaging oppressed groups in collective democratic theorizing about" their perceptions of oppression and privilege (Denzin, 1994, p. 509; Ponterotto, 2005b). Criticalist researchers employ both quantitative and qualitative methods in establishing a dialectical stance with respect to the researcherparticipant relationship that serves to empower the participants and stimulate transformation of oppressive conditions to more equitable ones. It is the critical theory paradigm that is most closely aligned with the mission of the Journal for Social Action in Counseling and Psychology (JSACP) given its goal of bridging the divide between theory and practice and stimulating social transformation and participant and community empowerment.

When referring to "multiculturalism" throughout this article, we recognize the broad definition of the concept to include ethnicity, race, gender, language, sexual orientation, age, body size, disability, education, spiritual or religious orientation, socioeconomic class, education, as well as other cultural dimensions (see American Psychological Association, 2003). In defining social justice research we adapt Crethar, Rivera, and Nash's (2008, p. 270) definition of social justice counseling as follows:

Social justice research represents a multifaceted approach to research in which investigators strive to simultaneously promote human development and the common good through addressing challenges related to both individual and distributive justice. Social justice research includes empowerment of the individual as well as the active confrontation of injustice and inequality in society because they affect research participants as well as those in their systematic contexts. 
Social justice researchers attend to the principles of equity, access, participation, and harmony defined in Crethar et al. (2008) and applied to qualitative and quantitative research in the preceding articles in this issue (Cokley \& Awad, 2013; Lyons et al., 2013). Social justice perspectives have emerged as a cornerstone of counseling training, research, and practice (Goodman \& West-Olatunji, 2009; Hays, Arredondo, Gladding, \& Toporek, 2010; Ratts, Toporek, \& Lewis, 2010; Singh, Hofsess et al., 2010; Singh, Urbano, Haston, \& McMahon, 2010; Toporek, Gerstein, Fouad, Roysircar, \& Israel, 2006). Naturally, the first step in designing and conducting social justice-oriented mixed methods research is enhancing one's multicultural awareness and developing a social justice perspective (i.e., adopting the critical theory paradigm; Ponterotto, 2010) in unimethod qualitative and quantitative research (Cokley \& Awad, 2013; Lyons et al., 2013). A second step to designing strong mixed methods social justice research involves developing competence in quantitative and qualitative research procedures as well as the philosophical paradigms that undergird each methodology.

We are reminded of the wisdom of Maori "elder" Smith (1999, p. 1), who noted: "the term 'research' is inextricably linked to European imperialism and colonialism ... The ways in which scientific research is implicated in the worst excesses of colonialism remains a powerful remembered history for many of the world's colonized peoples" (cited in Hill, Pace, \& Robbins, 2010, p. 17). Though counseling and psychological research has been dominated by the postpositivist research paradigm and associated quantitative methods, Smith's (1999) caution relates to all research paradigms and inquiry models. It is important to emphasize that no specific research paradigm or method is, de facto, more socially just, as socially just research is anchored in the multicultural awareness of the researcher and not in the research method (see Casas, 1985). With this caution regarding "western" research methods in hand, let us examine more closely the challenges and prevalence of mixed methods research in psychology.

\section{Challenges and Growing Popularity of Mixed Methods Research}

The incorporation of mixed methods design in psychology research is not new. The renowned research methodologists Campbell and Stanley (1966) promoted the use of mixed methods designs for topical exploration some five decades ago. Patton (1981) highlighted the value of mixed methods research in all forms of program evaluation, while Denzin (1978) advocated multiple methodologies to enhance the overall validity and credibility of research findings and interpretation (see Giddings, 2006 for historical review). It was not until the 1990s, however, that mixed methods began its push into mainstream research literature and training. Leading the promotion of mixed methods were the influential writing and research programs of Creswell (1994) and Tashakkori and Teddlie (1998), who can be designated the "modern parents" of the mixed methods movement in psychological research.

Though in the 1990s and early 2000's there were a number of influential researchers advocating for the use of mixed methods designs in psychological research, the appearance of published mixed methods studies in human services-oriented journals was slow in coming. For example, a classification of 868 empirical studies published in three counseling journals from 1995 though 2005 revealed that only 2\% incorporated 
mixed methods approaches (Ponterotto, Kuriakose, \& Granovskaya, 2008). Another content analysis of four health services journals inclusive of 1,651 empirical articles published from 2003-2007 found that 2.9\% utilized mixed methods designs (Wisdom et al., 2012). Finally, an analysis of 1,745 empirical articles published from 2002-2008 in three behavioral services journals found only $1.8 \%$ to rely on mixed methods designs (Lopez-Fernandez \& Molina-Azorin, 2011).

Generally speaking, mixed methods designs in human services research have been avoided for a number of reasons. First, given they combine qualitative and quantitative methods in a single study, and given the profession's long-standing preference for quantitative research (and the positivist and postpositivist research paradigms), few scholars have embraced procedures that combine the methods (see Lonner, 2009). Second, only a minority of psychological researchers have had adequate training in mixed methods designs, owing in part, to the absence of rigorous training in philosophy of science and qualitative methods in most North American counseling or psychology doctoral programs (Madill \& Gough, 2008; Ponterotto, 2005a, 2005c). Of note, is the finding that the status and embrace of qualitative research has been greater in the United Kingdom than in the North America (see Harper, 2012; Ponterotto, 2005a).

Third, numerous scholars have cautioned against mixed method designs for fear that one or the other design would be diluted by trying to do too much in a single study (Chwalisz, Shah, \& Hand, 2008; Ponterotto \& Grieger, 2007). The fourth and perhaps most potent caution against mixed methods designs is that quantitative and qualitative methods may hail from such disparate research paradigms that to combine them in a single study is illogical on philosophical grounds (Giddings, 2006; Sciarra, 1999). This challenge has been labeled the "incompatibility hypothesis" and has led to the "paradigm wars" in the 1970s and 1980s (Karasz \& Singelis, 2009, pp. 909-910).

Despite some of these challenges to increasing the use of mixed methods research in counseling and psychology, the momentum for their use continues to build, particularly in the last 10 years. Integrated reviews of mixed methods research have now appeared in the counseling (e.g., Hanson, J. W. Creswell, Plano Clark, Petska, \& J. D. Creswell, 2005; Plano Clark \& Wang, 2010), community-based (Badiee et al., 2012), health services (Wisdom et al., 2012), culture-specific psychological (Bartholomew \& Brown, 2012), and behavioral science (Lopez-Fernandez \& Molina-Azurin, 2011) literatures.

A major breakthrough in the acknowledgement and acceptance of mixed methods research in psychology and health was signaled in August 2011, when the National Institutes of Health released "Best Practices for Mixed Methods Research in the Health Sciences" (NIH, 2011). The linking of a specific research methodology to grant funding, particularly in a tight economy for such funding, goes a long way in promoting the study and use of mixed methods designs. The NIH document writing team was led by John Creswell and serves as a highly practical guide for designing, conducting, and reporting mixed methods research in a variety of human services and health professions. The guide includes critical tips for incorporating mixed methods designs into Federal Grant applications. Given social justice research focuses on community change and system transformation, topics of great interest to granting agencies, the new NIH guide will be useful to readers of the JSACP seeking grant funding. 


\section{Potential Benefits of Mixed Method Studies}

Carefully designed mixed methods studies offer a valuable investigative tool to researchers studying a wide variety of psychological topics across and within cultures (Bartholomew \& Brown, 2012). The flexibility inherent in mixed methods studies can result in a more holistic and accurate understanding of the phenomena under study. Mixed methods research can also advance the counseling and psychology professions' growing commitment to social justice research in that the use of carefully sequenced diverse methods can provide researchers with multiple windows into the lives of the less empowered and historically silenced within our society. Through these windows will emerge opportunities for social transformation and participant community empowerment. Similarly, mixed methods research can shed light on the complex dynamics of "privilege" in society. Creating a more just and equitable society necessitates a research focus on both our marginalized citizens (for empowerment) and those with unearned privilege (for critical awareness) (see Spanierman \& Soble, 2010; Vazquez, 2001).

Most researchers would agree that all research methods have inherent limitations. Thus, by systematically combining alternate methodologies in a given study, a researcher can compensate for uni-paradigmatic limitations and can, therefore, examine the topic in question with complementary depth and breadth (Anchin, 2008; Gelo, Braakmann, \& Benetka, 2008; Lonner, 2009). This broadened perspective of research purpose and method has been called the "compatibility hypothesis" and has led to the "third methodological way" (Karasz \& Singelis, 2009, pp. 909-910). The momentum and value of the "third methodological way" was conceptualized well by pioneering cross-cultural psychology researcher Walter Lonner (2009), who described the recent rapprochement of quantitative and qualitative methods:

Adherents to both of these orientations know how deeply layered and complex culture can be, and usually is ... Most believe, as I do, that the qualitativequantitative distinction is a false dichotomy. The best cross-cultural psychological research can be richly informed by the insights and perspectives of those who prefer to use a variety (and often a mixture) of procedures, techniques, and methods that have been supported and used by psychologists whose thinking and research are guided by an intense interest in culture's influence on human thought and behavior. (p. 907).

A well executed mixed methods study is characterized by 1) convincing rationale for why a mixed methods design is appropriate; 2) explication of the research paradigm and philosophy of science parameters for each of the methods including a discussion of how the variant paradigms coalesce to enhance the study; 3 ) demonstrated expertise in both methodological components of the mixed design; 4) high multicultural awareness of the research team; 5) ethical vigilance that transcends both the quantitative and qualitative components; and 6) strong writing that incorporates "thick description" (Ponterotto, 2006) of the qualitative component, and objective precision in the quantitative component with a fluid integration of the findings across methods. 
Furthermore, mixed methods research resonates with applied psychologists, particularly counseling researchers, because "combining quantitative and qualitative information also mirrors the process counselors use in practice when they merge quantitative assessments with qualitative information about a client's experiences and the meaning of those experiences" (Plano Clark \& Wang, 2010, p. 428). One can see the benefit of such an approach to social justice advocacy as a deeper understanding of the participants' oppressive (or privileged) life experiences can be reached and empowerment (or power sharing) strategies developed. Furthermore, counseling focused action research operates from a conceptual anchor of strength within the community and the need to incorporate life-span based prevention and psychoeducation goals in the research process (Fouad, Gerstein, \& Toporek, 2006).

\section{Value of Mixed Methods Designs for Multicultural and Social Justice Research}

Mixed methods designs capitalize on the complementary strengths of both quantitative and qualitative research in the same study. The quantitative component of a mixed methods study can a) promote wide, representative sampling within subcultures of multicultural communities and within marginalized communities in dominant cultural systems; b) reliably study cause-and-effect relationships among multicultural and social justice constructs; c) verify theory by confirming or disconfirming hypotheses generated from extant multicultural theories; d) anchor a portion of the findings in the statistical tradition that may be more familiar to positivist- and postpositivist-oriented journal editors and grant reviewers; e) summarize extensive numerical data in clear tabular form; and f) bolster the impact of small sample qualitative findings by documenting the "representativeness" of oppressive conditions in larger representative samples (see also Johnson \& Onwuegbuzie, 2004; Leech \& Onwuegbuzie, 2010). Given detailed discussions of exemplary multicultural and social-justice oriented quantitative research are readily available in the literature (Awad \& Cokley, 2010; Quintana, Troyano, \& Taylor, 2001; Cokley \& Awad, 2013), and acknowledging that psychological research has been dominated by postpositivist quantitative designs (see Camic, Rhodes, \& Yardley, 2003; Nagata, Kohn-Wood, \& Suzuki, 2012), this section emphasizes the value of bolstering quantitative research with a qualitative component, particularly in the critical theory and constructivist research paradigms.

Strong rationales for increasing the level of constructivist and critical theory-oriented qualitative research in the human services professions have been provided (Lyons \& Bike, 2010; Morrow, Rakhsha, \& Castaneda, 2001; Plano Clark \& Wang, 2010; Ponterotto, 2005a) and are anchored in basic philosophy of science elements (see Duffy \& Chenail, 2008; Ponterotto, 2005b) of axiology (values and ethics), ontology (nature of reality), epistemology (researcher-participant relationship), and rhetorical structure (presentation of results to audiences). In regard to axiology, researchers' values directly and indirectly impact their work with participants and their cultural communities. At times, a postpositivist, individualism-focused quantitative research approach can be markedly inconsistent with the worldview of certain collectivist culture communities. Thus, a "social justice intent" on the part of a well-meaning researcher can result in continuing "social oppression" of historically marginalized groups. Mohatt and Thomas (2006) highlighted multiple incidents of axiology clashes between Western-trained 
quantitative researchers and Alaska Native communities around the topics of measurement and sampling. For example, with regard to random sampling, a linchpin of quantitative research, these authors noted:

Random sampling procedures violate a fundamental principle of every indigenous group with whom I have worked. It assumes that a statistical or mathematical rationale should determine whom we talk to or with whom we intervene. It is .... both exclusive and dangerous because not all members of the community would be included, and there would be no evidence of co-membership on the part of the researchers and therefore no sense of protection from harm. (Mohatt \& Thomas, 2006, pp. 110-111).

In the above quote, one can see how a sole reliance on postpositivist quantitative methods with a marginalized and oppressed group can violate the social justice principles of equity, access, participation, and harmony. Mohatt and Thomas (2006) demonstrate how easily well-intentioned researchers can violate social justice principles when crossing cultural boundaries. By contrast, critical theory anchored qualitative designs often give voice to previously disempowered, marginalized, and silenced groups who share their worldview and lived experiences in their own words, in their own way, and under conditions set forth through co-membership in the research endeavor. The essence of co-membership in the research endeavor is a hallmark of social justice oriented empirical inquiry.

With regard to ontology, constructivist and critical theory qualitative research often brings researchers into culturally diverse communities where they attempt to suspend or bracket their perception and interpretation of reality in order to learn about the reality and lived experiences of their participants. Thus, rather than working from the expectation of a single true reality (as in postpositivism), researchers are open to the existence of multiple, equally valid realities (constructivism), and/or a reality embedded in historic injustice (critical theory). By listening to and observing the lived experiences of participants in culturally diverse communities, researchers demonstrate respect and care for participants and earn their trust so necessary to a successful research process (Mohatt \& Thomas, 2006).

Focusing on epistemology, adding a constructivist and/or critical theory component to a study brings the researcher closer to participants through more intense interaction, such as through in-depth, face-to-face interviews and participant observation. This close personal contact serves to empower participants and simultaneously reduce the likelihood of researchers stereotyping or marginalizing participants. Furthermore, the dialogic and dialectic nature of constructivist and critical theory paradigms, respectively, lead to growth and transformation of both the researchers and participants, as well as to the empowerment of research participants and their possible emancipation from existing oppressive conditions (Ponterotto, 2005a, 2005b, 2010). Thus qualitative research, or a qualitative design component added to a quantitative study, can serve, in-and-of-itself as a social justice mechanism.

Finally, with regard to rhetorical structure, or how a summary of the study is presented to research participants and a wider audience, qualitative researchers often present the 
actual voices of their participants through vivid and in-depth quotes. These "voices" are presented authentically, without transformation to numerical weights. Reading the participants' quotes and the researchers' integration and synthesis of these quotes, provides a "thick description" (Ponterotto, 2006) of the study and allows readers to emotively connect with the participants as if they observed the lived experiences. With regard to critical theory (social justice) research, the "thick description" of participant injustice and disempowerment can lead readers of the report to be moved to social justice action. The poignancy of "thick description" writing in qualitative and mixed methods studies is one of the most powerful tools of the social justice-oriented researcher.

Thus, in summary, the qualitative component of a mixed methods study in multicultural counseling can a) reduce the likelihood of researchers imposing their ontological assumptions on to culturally diverse communities; b) enhance meaningful dialogue between "scientists" and participants; c) stimulate multicultural growth and transformation in both researchers and participants; d) honor participants through listening to their "voices," in their communities, under research conditions coordinated jointly by participant "elders" and researchers; e) empower participants and researchers to work toward emancipation from oppressive social and political conditions; f) lead to multicultural and social justice theory development; g) be written-up and presented in a rhetorical structure that can be clearly understood by participant communities; and $h$ ) by incorporating "thick description" in social justice research reports, effectively engage readers in a social justice considerations. Such research, conducted by culturally aware researchers, can markedly promote social justice principles advocated by counseling psychologists.

Taken together, social justice-oriented mixed methods designs have the advantage of closely engaging and empowering an oppressed community through highly descriptive qualitative methods (Lyons, Bike, Johnson, \& Bethea, 2012; Ojeda, Flores, Rosales Meza, \& Morales, 2012; Lyons et al., 2013), while also providing "hard" (numerical and inferential) evidence that may appeal to the larger political and funding sources influencing the community (Cokley \& Awad, 2013). Well coordinated, social justiceoriented mixed methods studies can enhance the professional and public understanding of ongoing oppressive conditions among growing numbers of world citizens, and empower more widespread social justice application than can either quantitative or qualitative methods independently.

\section{Mixed Methods Designs}

Hanson et al. (2005) summarized philosophical stances on the use of mixed methods research and they outline specific mixed methods designs. The Methodological Purist believes that quantitative and qualitative methods hail from differing, mutually exclusive research paradigms anchored in different philosophy of science parameters (e.g., ontology, epistemology, axiology), and that therefore combining the two methods in a single study does not make sense on philosophical grounds (e.g., Sciarra, 1999). The Methodological Situationalist equally values quantitative and qualitative methodologies and their underlying philosophies of science, but believes that certain methods are more 
appropriate under certain circumstances, and that the design chosen should be dependent on the context of the research question and the state of knowledge on the topic at the time (e.g., Ponterotto et al., 2008). Finally, the Methodological Pragmatist believes that regardless of the circumstances of the research study, both qualitative and quantitative methods can be used in a given study (e.g., Johnson \& Onwuegbuzie, 2004). The present authors espouse the philosophy of Methodological Situationalism, and propose that under certain circumstances a research question may lend itself to mixed methods investigation.

Hanson et al. (2005) presented a concise summary of the following six mixed methods designs. In Sequential Explanatory designs, there is no specific advocacy or critical theory lens (e.g., feminism, critical race theory) to guide the study and the quantitative portion of the study precedes and is prioritized over the qualitative component. Sequential Exploratory designs are also free from an anchoring advocacy lens, but in this design the qualitative data is collected first and usually has primary weight in study interpretation. Sequential Transformative designs are guided by an advocacy lens, and the quantitative and qualitative components of the study can vary in terms of order and priority weighting. In the Concurrent Triangulation design, the qualitative and quantitative data is collected around the same time, and the weighting priority is usually equal across approaches. Concurrent Nested designs also involve simultaneous data collection, but either the quantitative or qualitative component is given interpretive priority. Finally, in Concurrent Transformative designs, a specific advocacy (criticalideological) lens is used to guide the study, the diverse data is collected concurrently, and the quantitative and qualitative components can be given the same or unequal interpretive weights.

In presenting the chosen mixed method design to the readership (see Table 1), standard notations are used to indicate both the timing and weight of the separate research components. For example, the sequential "qual $\rightarrow$ QUAN" notation shows that a less emphasized qualitative component leads directly to a prioritized quantitative component; and the concurrent "QUAL + QUAN" notation signifies that the quantitative and qualitative components of the study were conducted simultaneously and have equally strong emphases. Though there other typologies or classifications of mixed methods designs (e.g., Leech \& Onwuegbuzie, 2009; Onwuegbuzie \& Collins, 2007; Teddlie \& Tashakkori, 2006), it is the organizing system of Hanson et al. (2005) that has guided a majority of recent human services-focused mixed methods research.

\section{Samples of Mixed Methods Multicultural Research}

Recently, Plano Clark and Wang (2010) examined the use of mixed methods designs in multicultural counseling research. These authors identified 11 studies (from 2000 to 2007) covering cultural adaptation, multicultural competence, and programs for combating oppression. Of this group of studies, five were considered "one-phase" models in that the qualitative and quantitative research was conducted concurrently; four were considered "multi-phase" models given that distinct designs were implemented sequentially in two or three phases; and two were "embedded" models where researchers conducted primarily quantitative studies with a qualitative component 
embedded within to enhance data interpretation. Plano Clark and Wang's (2010) integrative review uncovered seven defining features of exemplary mixed methods multicultural studies: "defining the problem based on experiences and need for social change," "selecting methods that best fit with the study topic and participants," "using multicultural research teams," "collaborating with gatekeepers," "acknowledging researcher subjectivity," "considering linguistic differences," and "being sensitive to within group cultural contexts" (pp. 434-435).

To extend and build from Plano Clark and Wang's (2010) review, we conducted a more recent review of mixed methods studies in multicultural counseling/health issues. Our initial literature review was conducted in 2010 and covered the years 2007 through 2009; an updated review was conducted in early 2011 to include 2010 publications. Collectively we identified 23 mixed methods studies published from 2007 through 2010. To locate the studies we relied on PsycINFO and ERIC data base searches using varying combinations of the following search terms: mixed methods, quantitative and qualitative, multicultural, culture, social justice. Table 1 lists the study authors, topical focus, sample size (for quantitative and qualitative components), and design classification, including method prioritization and phases (Creswell \& Plano Clark, 2007; Plano Clark \& Wang, 2010).

The studies outlined in Table 1 represent a wide variety of national and international journals, and the samples studied hailed from throughout the United States, Europe, Africa, the Middle East, and Asia. With regard to specific mixed methods designs, concurrent triangulation and concurrent transformative were the most common. The most popular quantitative designs relied on established psychological instruments and study-specific questionnaires, and used analog-experimental, correlational, regression, factor analysis, and pretest-posttest analyses of the numerical data. The most frequent qualitative tools were semi-structured face-to-face interviews (of varying lengths) and focus groups; however, participant observation, reflective and autobiographical writing, theme analysis of open-ended responses, archival and artifact analysis, and identity maps were also incorporated. Particular qualitative approaches employed were grounded theory, phenomenology, consensual qualitative research, and case study.

In reviewing the publications in Table 1 (at end of this article), we generally found that the unique design contributions inherent in these studies aligned themselves well with the seven defining characteristics of strong multicultural mixed methods research identified by Plano Clark and Wang (2010) and reviewed earlier. The identified studies examined a wide range of multicultural issues such as understanding and describing culturally specific constructs such as depression and stress (Karasz, Gracia, \& Ferri, 2009; Nastasi et al., 2007); providing in-depth explorations of multicultural development and critical incidents among teacher trainees and practicing mental health practitioners (Agnew, Mertzman, Longwell-Grice, \& Saffold, 2008; Delsignore et al., 2010; Kyles \& Olafson, 2008); understanding cultural traditions and immigration adjustment along with their impact on behavior and psychological functioning (Castro \& Coe, 2007; Roer-Strier \& Kurman, 2009); identifying similarities and differences in development and social roles in cross-cultural comparisons (Guest, 2007; Keller \& Otto, 2009); studying in-depth socially and culturally sensitive topics such as dating, sexual attitudes, body image, and health behaviors (Lau et al., 2009; Medlinger \& Cwikel, 2008; Sinha, Curtis, Jayakody, 
Viner, \& Roberts, 2007; Viladrich, Yeh, Bruning, \& Weiss, 2008); understanding racial, ethnic, religious, and sexual identity development (Charmaraman \& Grossman, 2010; Rodriguez, Schwartz, \& Whitbourne, 2010; Schweizer, Brunner, Schutzmann, Schonbucher, \& Richter-Appelt, 2009; Sirin \& Fine, 2007; Sirin, Bikmen, Fine, Zaal, \& Katsiaficas, 2008); studying the impact of trauma, loss and grief, and psychological coping and resilience (Tuicomepee \& Romano, 2008); understanding bias in traditional psychopathology assessment through indigenous cultural perspectives, and understanding the process and bias in clinical decision making (Hays, Prosek, \& McLeod, 2010; Hill et al., 2010); and understanding in-depth the needs, coping, and attitudes of homeless emerging adults and emancipated foster youth (Mares, 2010; Thompson, Barczyk, Gomez, Dreyer, \& Popham, 2010).

In all of the studies cited above, the mixed methods designs provided a depth and breadth of coverage and cultural understanding that likely could not have been accomplished through uni-method designs. The quantitative portion often provided explanatory and generalizability benefits, while the qualitative portion provided a depth of understanding and more vivid description of a phenomena. These studies were very varied in topic, purpose, design and procedures, and all were peer-reviewed and of good quality. In addition to generally meeting the exemplary design criteria for mixed methods research presented by Plano Clark and Wang (2010) and reviewed earlier, we also found that in many cases the authors of our reviewed studies a) had mastery of both the quantitative and qualitative research on the topic at hand; b) presented strong rationales for the study and for their decision to mix research methods; c) appeared to have team members with expertise in quantitative and qualitative methods; d) wrote in a clear and concise manner even when including extensive participant quotes; e) were detailed in noting their design and study limitations; and f) could point clearly to needed follow-up research using quantitative, qualitative, and mixed methods designs.

Among the studies summarized in Table 1 (at end of this article) that had a particularly strong social justice orientation and that incorporated many of the defining characteristics of both exemplary quantitative (Awad \& Cokley, 2010; Cokley \& Awad, 2013) and qualitative (Lyons \& Bike, 2010; Lyons et al., 2013) multicultural research were: Hill et al.'s (2010) "decolonizing personality assessment" study (MMPI-2 comparative group item analysis followed by long interviews); Hays et al. (2010) investigation of cultural bias in clinical decision making and diagnosis (written case study-manipulated experimental analog method and semi-structured interviews); Sirin and Fine's (2007) "hyphenated selves" study which examined how Muslim youth negotiate their identity and coped with discrimination in the aftermath of the September 11, 2001 attacks on the US (survey instruments, focus groups, and identity maps [i.e., pictorial drawing of self identity]); Thompson et al.'s (2010) study of the role of substance use in the coping of homeless emerging adults (semi-structured interviews followed by self-report measures); and Sinha et al.'s (2007) sexual health study among East London minority adolescents (focus groups and some interviews). Each of these studies focused on timely issues in social justice and balanced well the complementary strengths of constructivist or critical theory qualitative methods with postpositivist quantitative procedures 


\section{Considerations in Deciding Whether to Incorporate a Mixed Methods Design}

P. Paul Heppner and his colleagues (Heppner \& Heppner, 2004; Heppner, Wampold, \& Kivlighan, 2008) have outlined stimulus questions that researchers can ask themselves as they consider what methodology, quantitative or qualitative, may be most appropriate to their study goals. We have adapted and extended this self-reflective process to mixed method research considerations. More specifically, Figure 1 below presents a flow diagram to help the researcher gauge important considerations in deciding whether to use a mixed methods design for his or her study. Our model originated from the second author's experiences in conducting her doctoral dissertation (Mathew, 2011). However, the flow diagram can assist researchers at various levels of training, experience, and professional development.

An assumption inherent in the diagram model is that the researcher has the prerequisite multicultural and social justice competence to engage in counseling research. Ponterotto and Grieger (2008) outlined 32 specific competencies required of all multicultural counseling researchers. These competencies extend the 34 multicultural counseling competencies outlined in Sue et al. (1998). The multicultural research competencies are organized into five broad areas: researcher self-awareness as a cultural being; knowledge of past psychological and health research with minority populations (e.g., unethical Tuskegee syphilis study in Alabama); community consultation and responsibility; ethical research practice; and knowledge of philosophy of science and research paradigms, with bi-methodological competence in quantitative and qualitative methods. Therefore, a prerequisite skill base for engaging in any multicultural counseling research is knowledge, experience, and/or supervision in the counseling-specific and research-specific competency sets (Ponterotto \& Grieger, 2008; Sue et al., 1998). Importantly, consistent with counseling's growing commitment to social justice and advocacy efforts, the competency sets include a number of social justice focused competencies.

The Mixed Method Considerations Diagram below considers five broad areas and begins with a series of questions: First, does the topic at hand, and the accumulated research to date, lead to a research question that can best be answered by a mixed methods design? Second, how will a mixed methods design facilitate the overarching research goals of social justice in terms of community reflection and transformation? In addition to these broad questions, it would behoove the social justice researcher to address more specific rationales for their mixed methods study (see NIH, 2011). For example, Bryman (2006) outlined 16 justifications for mixed methods studies identified in a broad review of 232 mixed methods studies in the social sciences. More recently, Leech and Onwuegbuzie (2010) discussed four rationales for mixed methods research in counseling. First is participant enrichment, where the goal is to optimize the study sample. Second is instrument fidelity, which aims to maximize the utility and appropriateness of the qualitative or quantitative instruments used in the study. Third is treatment integrity, where research methods are mixed to more faithfully assess interventions, treatments, or programs. Finally, the fourth mixed methods rationale is significance enhancement, the goal of which is to maximize the detail and accuracy of the results interpretation. 


\section{MIXED METHOD CONSIDERATIONS DIAGRAM}
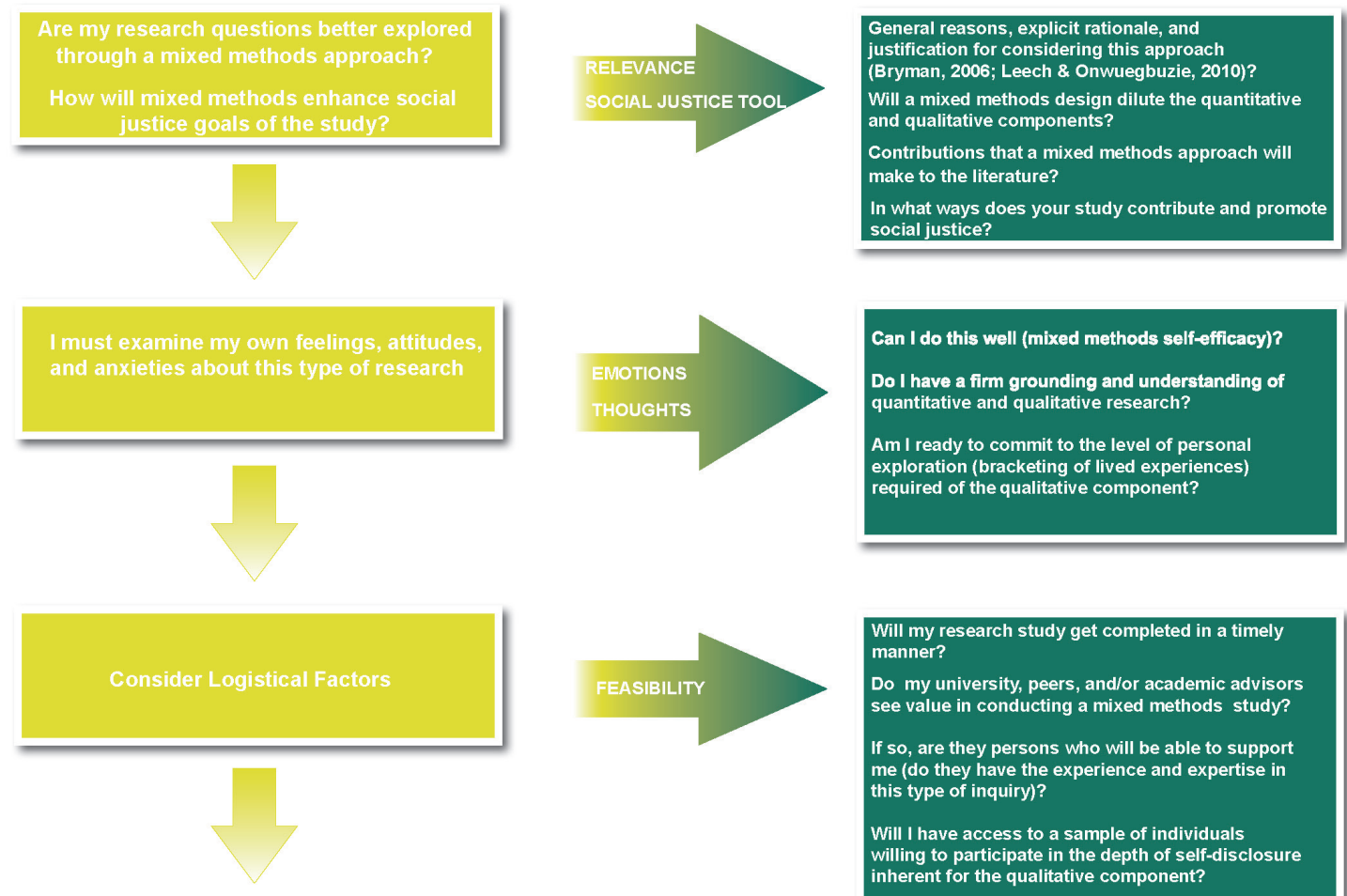

Can I do this well (mixed methods self-efficacy)?

Do I have a firm grounding and understanding of quantitative and qualitative research?

Am I ready to commit to the level of personal exploration (bracketing of lived experiences) required of the qualitative component?
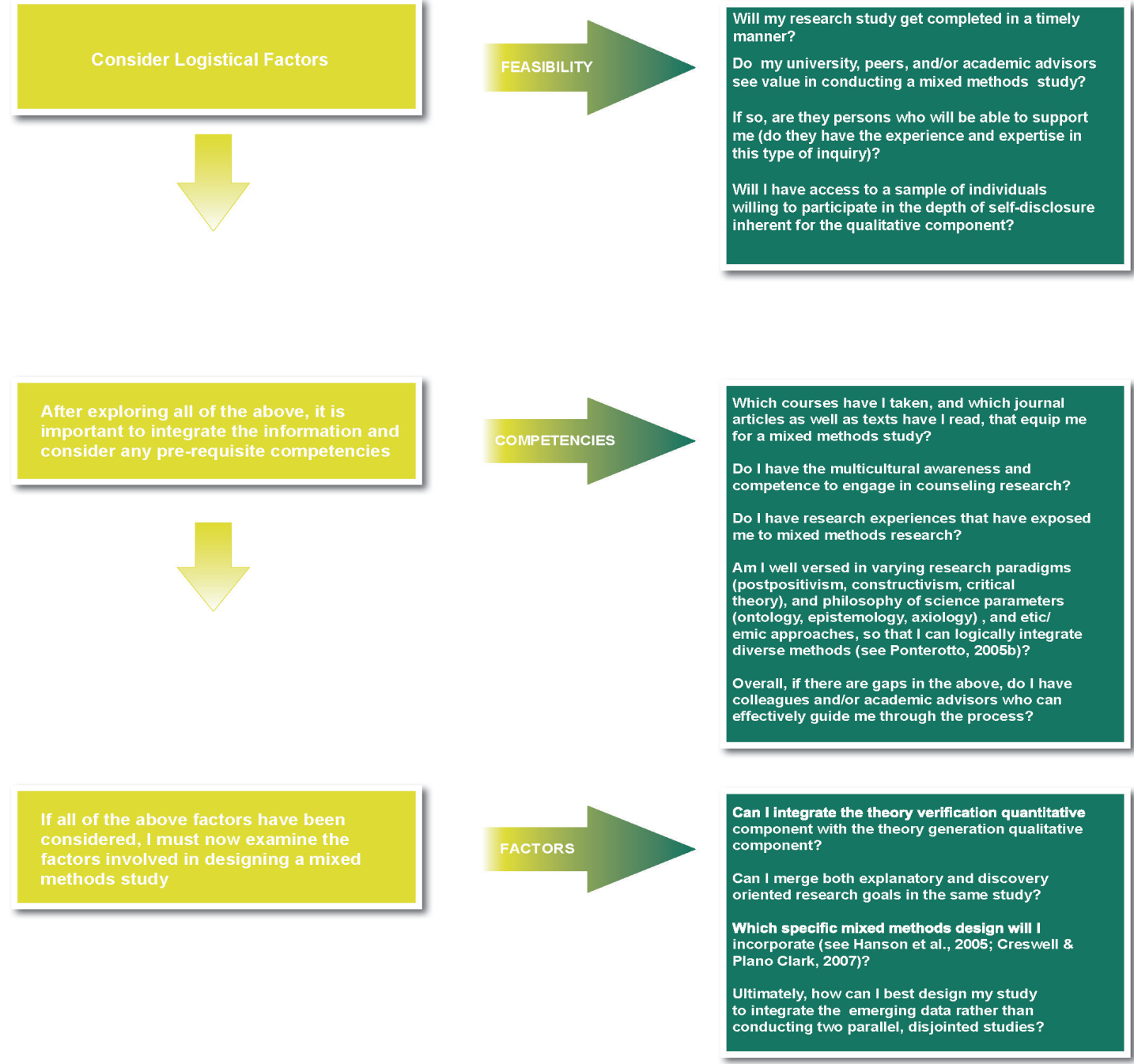
Though Leech and Onwuegbuzie (2010) were writing about mixed methods counseling research broadly, their four rationales can be applied specifically to multicultural social justice-focused research. For example, participant enrichment can ensure that a racial/ethnic/sexual minority sample is not stereotyped by providing both an in-depth qualitative sampling of a small group of participants and a more representative sampling in the quantitative portion. Instrument fidelity could apply to following up a quantitative scale or survey with in-depth interviews to ensure the voices and needs of the community under study are addressed. Treatment integrity could assure that the tested intervention in a multicultural community is assessed by both traditional pre-post outcome measures, as well as in process and end-of-treatment individual interviews and focus groups. Finally, significance enhancement would combine quantitative and qualitative methods to more fully understand and explain the challenges or oppression faced in a lower-income minority sample.

In the second box of the flow diagram, the researcher explores her or his own feelings and thoughts about engaging in mixed methods research. In essence, what is the researcher's self efficacy for this type of integrative research? At step three, the researcher considers logistical realities in using a mixed methods design. In our example, a doctoral student may consider department support levels for mixed methods designs, as well as sampling and time-to-completion challenges. For pre-tenure professors, the researcher may consider the tenured faculty's opinions regarding scholarship and rigor levels of mixed methods designs. At the fourth level of the flow diagram there is a pointed assessment of one's competence to conduct the study. Finally, if the first four boxes of the model have been adequately addressed, the researcher decides on the specific mixed methods design to incorporate.

\section{Conclusion and Limitations}

This article has highlighted the potential value of incorporating mixed methods designs into counseling research generally, and multicultural/social justice focused research specifically. Prerequisite conditions for a mixed methods design rationale include: a) that the specific research question, in light of accumulated evidence on the topic, lends itself to both quantitative (positivist/postpositivist) and qualitative (constructivist or critical theory) research lenses; $b$ ) that the researcher has competence in both quantitative and qualitative research and their underlying philosophy of science anchors; and c) that the researcher has undergone multicultural self-reflection and supervised multicultural counseling and research experience. By selectively adopting the methodology "compatibility hypotheses" and walking the path of the "third methodological way" (Karasz \& Singelis, 2009, pp. 909-910), the field of counseling psychology, generally, and multicultural and social justice psychology, specifically, can advance in significant ways.

Despite the promise of mixed methods designs to research in counseling and psychology, readers are cautioned as to the limitations of these methods. Chief among them is the danger of trying to accomplish too much in a single study and therefore 
diluting both the quantitative ands qualitative components of the research design. Second, though the qualitative component of the mixed method study is more likely to "give voice" to and empower marginalized groups, the social justice anchor of the research study lies in the multicultural awareness and competence of the researcher rather than with a component of the research method. Without high levels of multicultural competence of the researcher, both quantitative and qualitative procedures run the risk of further marginalizing and oppressing minority groups (see Mohatt \& Thomas, 2006; Nagata et al., 2012). Third, there exists the possibility that mixed methods designs can continue to promote quantitative research within the positivist and postpositivist research paradigms, though in more subtle ways. Giddings (2006) presented this view in an article titled "Mixed-methods research: Positivism dressed in drag?" This author warned of the dangers of jumping on the mixed methods bandwagon without further discussion of underlying research paradigms. Giddings's view reminds the social justice researcher of the shift from "old-fashioned" or "overt" racism to the more subtle "aversive" or "modern" racism. Giddings asks: Is mixed methods research simply a more politically correct way to continue to promote a positivist emphasis in research?

In addition to the limitations of mixed methods designs generally, the present article also has limitations. We have purposely provided broad coverage of a number of related topics - research paradigms and philosophy of science, variant research methods, social justice perspectives, sample mixed methods studies, deciding on a mixed method design - at the expense of providing a focused depth of coverage. As such, one direction for follow-up writing in the area might be to select a small sample of four or five mixed methods, social justice oriented studies and deconstruct the purpose, design, and procedures to outline exemplary characteristics of the studies to guide future research. In closing, we hope this article serves to stimulate more thinking and writing in the area of methodological pluralism.

\section{Contact information}

Joseph G. Ponterotto, Professor of Education and Coordinator of the Mental Health Counseling Program, Division of Psychological and Educational Services, Graduate School of Education, Fordham University at Lincoln Center

Email: ponterotto@fordham.edu

Jaya T. Mathew, Clinical Instructor, Counseling Psychology Department, School of Education, University of Wisconsin

Brigid Raughley, doctoral student, Counseling Psychology, Mental Health Counseling Program, Division of Psychological and Educational Services, Graduate School of Education, Fordham University at Lincoln Center 


\section{References}

Agnew, M., Mertzman, T., Longwell-Grice, H., \& Saffold, F. (2008). Who's in, who's out: Examining race, gender and the cohort community. Journal of Diversity in Higher Education, 1, 20-32.

American Psychological Association. (2003). Guidelines on multicultural education, training, research, practice, and organizational change for psychologists. American Psychologist, 58, 377-402.

Anchin, J.C. (2008). Contextualizing discourse on a philosophy of science for psychotherapy integration. Journal of Psychotherapy Integration, 18, 1-24.

Awad, G. H., \& Cokley, K. O. (2010). Designing and interpreting quantitative research in multicultural counseling. In J. G. Ponterotto, J. M. Casas, L. A. Suzuki, \& C. M. Alexander (Eds.), Handbook of multicultural counseling. ( ${ }^{\text {rd }}$ ed., pp. 385-396). Los Angeles, CA: Sage.

Badiee, M., Wang, S. C., \& Creswell, J. W. (2012). Designing community-based mixed methods research. In D. K. Nagata, L. Kohn-Wood, \& L. A. Suzuki (Eds.), Qualitative strategies for ethnocultural research (pp. 41-59). Washington, DC: American Psychological Association.

Bartholomew, T. T., \& Brown, J. R. (2012). Mixed methods, culture, and psychology: A review of mixed methods in culture-specific psychological research. International Perspectives in Psychology: Research, Practice, Consultation, 1, 177-190.

Bryman, A. (2006). Integrating quantitative and qualitative research: How is it done? Qualitative Research, 6, 97-113.

Bryman, A. (2007). Barriers to integrating quantitative and qualitative research. Journal of Mixed Methods Research, 1, 8-22.

Camic, P. M., Rhodes, J. E., \& Yardley, L. (Eds.). (2003). Qualitative research in psychology: Expanding perspectives in methodology and design. Washington, DC: American Psychological Association.

Campbell, D. T., \& Stanley, J. C. (1966). Experimental and quasi-experimental designs for research. In N. L. Gage (Ed.), Handbook of research on teaching (pp. 1-76). Chicago: Rand-McNally.

Casas, J. M. (1985). A reflection on the status of racial/ethnic minority research. The Counseling Psychologist, 13, 581-598.

Castro, F., \& Coe, K., (2007). Traditions and alcohol use: A mixed-methods analysis. Cultural Diversity and Ethnic Minority Psychology, 13, 269-284. 
Charmaraman, L., \& Grossman, J. M. (2010). Importance of race and ethnicity: An exploration of Asian, Black, Latino, and multiracial adolescent identity. Cultural Diversity and Ethnic Minority Psychology, 16, 144-151.

Chwalisz, K., Shah, S. R., \& Hand, K. M. (2008). Facilitating rigorous qualitative research in rehabilitation psychology. Rehabilitation Psychology, 53, 387-399.

Clarke, P. (2009). Understanding the experience of stroke: A mixed-method research agenda. The Gerontologist, 49, 293-302.

Cokley, K. O., \& Awad, G. H. (2013). In defense of quantitative methods: Using the "master's tools" to promote social justice. Journal for Social Action in Counseling and Psychology.

Creswell, J. W. (1994). Research design: Qualitative and quantitative approaches. Thousand Oaks, CA: Sage.

Creswell, J. W., \& Plano Clark, V. L. (2007). Designing and conducting mixed methods research. Thousand Oaks, CA: Sage.

Crethar, H. C., Rivera, E. T., \& Nash, S. (2008). In search of common threads: Linking multicultural, feminist, and social justice counseling paradigms. Journal of Counseling \& Development, 86, 269-278.

Delsignore, A. M., Petrova, E., Harper, A., Stowe, A. M., Mu'min, A. S., \& Middleton, R. A. (2010). Critical incidents and assistance-seeking behaviors of White mental health practitioners: A transtheoretical framework for understanding multicultural counseling competency. Cultural Diversity and Ethnic Minority Psychology, 16, 352-361.

Denzin, N. K. (Ed.). (1978). Sociological methods: A sourcebook. New York: McGraw-Hill.

Denzin, N. K. (1994). The art and politics of interpretation. In N. K. Denzin \& Y. S. Lincoln (Eds.), Handbook of qualitative research (pp. 500-515). Thousand Oaks, CA: Sage.

Descartes, R. (1968). Discourse on method and meditations. Harmondsworth, England: Penguin. (Original work published 1637).

Dilthey, W. (1977). Descriptive psychology and historical understanding (R. M. Zaner \& K. L. Heiges, Trans.). The Hague, the Netherlands: Matinus Nijhoff. (Original work published 1894).

Duffy, M., \& Chenail, R. J. (2008). Values in qualitative and quantitative research. Counseling and Values, 53, 22-38. 
Filstead, W. J. (1979). Qualitative methods: A needed perspective in evaluation research. In T. D. Cook \& C. S. Reichardt (Eds.), Qualitative and quantitative methods in evaluation research (pp. 33-48). Beverly Hills, CA: Sage.

Fouad, N. A., Gerstein, L., \& Toporek, R. L. (2006). Social justice and counseling psychology in context. In R. L. Toporek, L. Gerstein, N. Fouad, G. Roysircar, \& T. Israel (Eds.). Handbook for social justice in counseling psychology: Leadership, vision, and action (pp. 1-16). Thousand Oaks, CA: Sage.

Gelo, O., Braakmann, D., \& Benetka, G. (2008). Quantitative and qualitative research: Beyond the debate. Integrative Psychological \& Behavioral Science, 42, 266-290.

Giddings, L. S. (2006). Mixed-methods research: Positivism dressed in drag? Journal of Research in Nursing, 11, 195-203.

Goodman, R. D., \& West-Olatunji, C. A. (2009). Applying critical consciousness: Culturally competent disaster response outcomes. Journal of Counseling \& Development, 87, 458-465.

Guba, E. G., \& Lincoln, Y. S. (1994). Competing paradigms in qualitative research. In N. K. Denzin \& Y. S. Lincoln (Eds.), Handbook of qualitative research (pp. 105117). Thousand Oaks, CA: Sage.

Guest, A. M. (2007). Cultures of childhood and psychosocial characteristics: Selfesteem and social comparison in two distinct communities. Ethos, 35, 1-32.

Hanson, W. E., Creswell, J. W., Clark, V. L. P., Petska, K. S., \& Creswell, J. D. (2005). Mixed methods research designs in counseling psychology. Journal of Counseling Psychology, 52, 224-235.

Harper, D. J. (2012). Surveying qualitative research teaching on British clinical psychology training programmes 1992-2006: A changing relationship? Qualitative Research in Psychology, 9, 5-12.

Hays, D. G., Arredondo, P., Gladding, S. T., \& Toporek, R. L. (2010). Integrating social justice in group work: The next decade. The Journal for Specialists in Group Work, 35, 177-206.

Hays, D. G., Prosek, E. A., \& McLeod, A. L. (2010). A mixed methodological analysis of the role of culture in the clinical decision-making process. Journal of Counseling \& Development, 88, 114-121.

Heppner, P. P., Wampold, B. E., \& Kivlighan, D. Jr. (2008). Research design in counseling ( $3^{\text {rd }}$ ed.). Pacific Grove, CA: Brooks/Cole.

Heppner, P. P., \& Heppner, M. J. (2004). Writing and publishing your thesis, dissertation, and research: A guide for students in the helping professions. Belmont, CA: Brooks/Cole -Thomas Learning. 
Hill, J. S., Pace, T. M., \& Robbins, R. R. (2010). Decolonizing personality assessment and honoring indigenous voices: A critical examination of the MMPI-2. Cultural Diversity and Ethnic Minority Psychology, 16, 16-25.

Johnson, R. B., \& Onwuegbuzie, A. J. (2004). Mixed methods research: A research paradigm whose time has come. Educational Researcher, 33, 14-26.

Kant, I. (1966). Critique of pure reason. Garden City, NY: Doubleday. (Original work published 1781).

Karasz, A., Garcia, N., \& Ferri, L. (2009). Conceptual models of depression in primary care patients: A comparative study. Journal of Cross-Cultural Psychology, 40, 1041-1059.

Karasz, A., \& Singelis, T. M. (2009). Introduction to the special issue: Qualitative and mixed methods research in cross-cultural psychology. Journal of Cross-Cultural Psychology, 40, 909-916.

Keller, H., \& Otto, H. (2009). The cultural socialization of emotion regulation during infancy. Journal of Cross-Cultural Psychology, 40, 996-1011.

Kincheloe, J. L., \& McLaren, P. L. (2000). Rethinking critical theory and qualitative research. In N. K. Denzin \& Y. S. Lincoln (Eds.), Handbook of qualitative research ( $2^{\text {nd }}$ ed., pp. 138-157). Thousand Oaks, CA: Sage.

Kohn-Wood, L., \& Diem, J. (2012). Novel approaches to qualitative methods with ethnocultural populations. In D. K. Nagata, L. Kohn-Wood, \& I. A. Suzuki (Eds.), Qualitative strategies for ethnocultural research (pp. 85-99). Washington, DC: American Psychological Association.

Kyles, C. R., \& Olafson, L. (2008). Uncovering preservice teachers' beliefs about diversity through reflective writing. Urban Education, 43, 500-518.

Lau, M., Markham, C., Lin, H., Flores, G., \& Chacko, M., (2009). Dating and sexual attitudes in Asian-American adolescents. Journal of Adolescent Research, 24, 91113.

Leech, N. L., \& Onwuegbuzie, A. J. (2009). A typology of mixed methods research designs. Quality and Quantity: International Journal of Methodology, 43, 265275.

Leech, N. L., \& Onwuegbuzie, A. J. (2010). Guidelines for conducting and reporting mixed research in the field of counseling and beyond. Journal of Counseling \& Development, 68, 61-69.

Locke, J. (1956). An essay concerning human understanding. Chicago: Henry Regnery (Original work published 1689). 
Lonner, W. J. (2009). Senior editor's introduction to the special issue: Qualitative and mixed methods research in cross-cultural psychology. Journal of Cross-Cultural Psychology, 40, 907-908.

Lopez-Fernandez, O., \& Molina-Azorin, J. F. (2011). The use of mixed methods research in the field of behavioural sciences. Qual Quant, 45, 1459-1472.

Lyons, H. Z., \& Bike, D. H. (2010). Designing and interpreting qualitative research in multicultural counseling. In J. G. Ponterotto, J.M. Casas, L.A. Suzuki, \& C.M. Alexander (Eds.), Handbook of multicultural counseling ( $3^{\text {nd }}$ ed., pp. 413425).Thousand Oaks, CA: Sage.

Lyons, H. Z., Bike, D. H., Johnson, A., \& Bethea, A. (2012). Culturally competent qualitative research with people of African descent. Journal of Black Psychology, $38,153-171$.

Lyons, H. Z., Bike, D., Ojeda, L., Rosales Meza, R., Johnson, A., \& Flores, L. Y. (2013). Qualitative research as social justice practice with culturally diverse populations. Journal for Social Action in Counseling and Psychology.

Madill, A., \& Gough, B. (2008). Qualitative research and its place in psychological science. Psychological Methods, 13, 254-271.

Mares, A. S. (2010). An assessment of independent living needs among emancipating foster youth. Child Adolescent Social Work Journal, 27, 79-96.

Mathew, J. T. (2011). Exploring the process of multicultural competence development and training of counselor trainees of color. Doctoral dissertation, Graduate School of Education. Fordham University, New York City, New York.

Medlinger, S., \& Cwikel, J. (2008). Spiraling between qualitative and quantitative data on women's health behaviors: A double helix model for mixed methods. Qualitative Health Research, 18, 280-293.

Mill, J. S. (1906). A system of logic. London: Longman (Original work published 1843).

Mohatt, G. V., \& Thomas, L. R. (2006). "I wonder, why would you do it that way?" Ethical dilemmas in doing participatory research with Alaska native communities. In J. E. Trimble \& C. B. Fisher (Eds.), The handbook of ethical research with ethnocultural populations \& communities (pp. 93-115). Thousand Oaks, CA: Sage.

Morrow, S. L., Rakhsha, G., \& Castaneda, C. L. (2001). Qualitative research methods for multicultural counseling. In J.G. Ponterotto, J.M. Casas, L.A. Suzuki, \& C.M. Alexander (Eds.), Handbook of multicultural counseling ( ${ }^{\text {nd }}$ ed., pp. 575-603). Thousand Oaks, CA: Sage. 
Nagata, D. N., Kohn-Wood, L., \& Suzuki, L. A. (Eds.). (2012). Qualitative strategies for ethnocultural research. Washington, DC: American Psychological Association.

Nastasi, B. K. Hitchcock, J. H., Burkholder, G., Varjas, K., Sarkar, S., \& Jayasena, A. (2007). Assessing adolescents' understanding of an reactions to stress in different cultures: Results of a mixed-methods approach. School Psychology International, 28, 163-178.

National Institutes of Health. (2011). Best practices for mixed methods research in the health sciences. Office of Behavioral and Social Sciences Research. Bethesda, MD.

Ojeda, L., Flores, L. Y., Rosales Meza, R., \& Morales, A. (2012). Culturally competent qualitative research with Latino immigrants. Hispanic Journal of Behavioral Sciences, 33, 184-203.

Onwuegbuzie, A. J., \& Collins, K. M. T. (2007). A typology of mixed methods sampling designs in social science research. The Qualitative Report, 12, 281-316.

Patton, M. Q. (1981). Practical evaluation. Beverly Hills, CA: Sage.

Pearce, L. D. (2012). Mixed methods inquiry in sociology. American Behavioral Scientist, 56, 829-848.

Plano Cark, V. L., \& \& Wang, S. C. (2010). Adapting mixed methods research to multicultural counseling. In J.G. Ponterotto, J.M. Casas, L.A. Suzuki, \& C.M. Alexander (Eds.), Handbook of multicultural counseling ( $3^{\text {rd }}$ ed., pp. 427438). Thousand Oaks, CA: Sage.

Ponterotto, J. G. (2005a). Integrating qualitative research requirements into professional psychology training programs in North America: Rationale and curriculum model. Qualitative Research in Psychology, 2, 97-116.

Ponterotto, J. G. (2005b). Qualitative research in counseling psychology: A primer on research paradigms and philosophy of science. Journal of Counseling Psychology, $52,126-136$.

Ponterotto, J. G. (2005c). Qualitative research training in counseling psychology: A survey of directors of training. Teaching of Psychology, 32, 59-61.

Ponterotto, J. G. (2006). Brief note on the origins, evolution, and meaning of the qualitative concept of "thick description." The Qualitative Report, 11, 538-549.

Ponterotto, J. G. (2010). Qualitative research in multicultural psychology: Philosophical underpinnings, popular approaches, and ethical considerations. Cultural Diversity and Ethnic Minority Psychology, 16, 581-589. 
Ponterotto, J. G., \& Grieger, I. (2007). Effectively communicating qualitative research. The Counseling Psychologist, 35, 404-430.

Ponterotto, J. G., \& Grieger, I. (2008). Guidelines and competencies for cross-cultural counseling research. In P. B. Pedersen, J. G. Draguns, W. L. Lonner, \& J. E. Trimble (Eds.), Counseling across cultures ( $6^{\text {th }}$ ed., pp. 57-72). Thousand Oaks, CA: Sage.

Ponterotto, J. G., Kuriakose, G., \& Granovskaya, Y. (2008). Counseling and psychotherapy. In C. Willig \& W. Stainton-Rogers (Eds.), The Sage handbook of qualitative research in psychology (pp. 455-471). London: Sage.

Popper, K. (1968). Conjectures and refutations. New York: Harper \& Row.

Quintana, S. M., Troyano, N., \& Taylor, G. (2001). Cultural validity and inherent challenges in quantitative methjods for multicultural research. In J. G. Ponterotto, J. M. Casas, L. A. Suzuki, \& C. M. Alexander (Eds.), Handbook of multicultural counseling ( $2^{\text {nd }}$ ed., pp. 604-630). Thousand Oaks, CA: Sage.

Ratts, M. J., Toporek, R. L., \& Lewis, J. A. (2010). ACA advocacy competencies: A social justice framework. Alexandria, VA: American Counseling Association.

Rodriguez, L., Schwartz, S. J., \& Whitbourne, S. K. (2010). American identity revisited: The relation between national, ethnic, and personal identity in a multiethnic sample of emerging adults. Journal of Adolescent Research, 25, 324-349.

Roer-Strier, D., \& Kurman, J. (2009). Combining qualitative and quantitative methods to study perceptions of immigrant youth. Journal of Cross-Cultural Psychology, 40, 988-995.

Schweizer, K., Brunner, F., Schutzmann, K., Schonbucher, V., \& Richter-Appelt, H. (2009). Gender identity and coping in female 46, XY adults with androgen biosynthesis deficiency (intersexuality/DSD). Journal of Counseling Psychology, 56,189-201.

Sciarra, D. T. (1999). The role of the qualitative researcher. In M. Kopala \& L. A. Suzuki (Eds.), Using qualitative methods in psychology (pp. 37-48). Thousand Oaks, CA: Sage.

Singh, A. A., Hofsess, C. D., Boyer, E. M., Kwong, A., Lau, A. S. M., McLain, M., \& Haggins, K. L. (2010). Social justice and counseling: Listening to the voices of doctoral trainees. The Counseling Psychologist, 38, 766-795.

Singh, A. A., Urbano, A., Haston, M., \& McMahon, E. (2010). School counselors' strategies for social justice change: A grounded theory of what works in the real world. Professional School Counseling, 13, 135-145. 
Sinha, S., Curtis, K., Jayakody, A., Viner, R., \& Roberts, H. (2007) People make assumptions about our communities: Sexual health amongst teenagers from Black and minority ethnic backgrounds in East London. Ethnicity and Health, 12, 423- 441.

Sirin, S., Bikmen, N., Fine, M., Zaal, M., \& Katsiaficas, D. (2008) Exploring dual identification among Muslim-American emerging adults: A mixed methods study. Journal of Adolescence, 31, 259-279.

Sirin, S., \& Fine, M. (2007) Hyphenated selves: Muslim American youth negotiating identities. Applied Development Science, 11, 151-163.

Smith, L. T. (1999). Decolonizing methodologies: Research and indigenous peoples. New York: Zed Books.

Spanierman, L. B., \& Soble, J. R. (2010). Understanding whiteness: Previous approaches and possible directions in the study of white racial attitudes and identity. In J. G. Ponterotto, J. M. Casas, L. A. Suzuki, \& C. M. Alexander (Eds.), Handbook of multicultural counseling ( $3^{\text {rd }}$ ed., pp. 283-299). Los Angeles, CA: Sage.

Sue, D. W., Carter, R. T., Casas, J. M., Fouad, N. A., Ivey, A. E., Jensen, M., LaFromboise, T. D., Manese, J., Ponterotto, J.G., \& Vazquez-Nutall, E. (1998). Multicultural counseling competencies: Individual and organizational development. Thousand Oaks, CA: Sage.

Tashakkori, A., \& Teddlie, C. (1998). Mixed methodology: Combining qualitative and quantitative approaches. Thousand Oaks, CA: Sage.

Teddlie, C., \& Tashakkori, A. (2006). A general typology of research designs featuring mixed methods. Research in the Schools, 13, 12-28.

Thompson, S. J., Barczyk, A. N., Gomez, R., Dreyer, L., \& Popham, A. (2010). Homeless, street-involved emerging adults: Attitudes toward substance use. Journal of Adolescent Research, 25, 231-257.

Toporek, R. L., Gerstein, L. G., Fouad, N. A., Roysircar, G., \& Israel, T. (Eds.). (2006). Handbook for social justice in counseling psychology: Leadership, vision, and action. Thousand Oaks, CA: Sage.

Tuicomepee, A., \& Romano, J. (2008). Thai adolescent survivors 1 year after the 2004 Tsunami: A Mixed Methods study. Journal of Counseling Psychology, 55, 308320.

Vasquez, M. J. T. (2001). Reflections on unearned advantages, unearned disadvantages, and empowering experiences. In J. G. Ponterotto, J. M. Casas, L. A. Suzuki, \& C. M. Alexander (Eds.), Handbook of multicultural counseling $\left(2^{\text {nd }}\right.$ ed., pp. 64-77). Thousand Oaks, CA: Sage. 
Viladrich, A., Yeh, M-C, Bruning, N., \& Weiss, R. (2008). "Do real women have curves?" Paradoxical body images among Latinas in New York City. Journal of Immigrant Minority Health, 11, 20-28.

Wisdom, J. P., Cavaleri, M. A., Onwuebbuzie, A. J., \& Green, C. A. (2012). Methodological reporting in qualitative, quantitative, and mixed methods health services research articles. Health Services Research, 47, 721-745. 


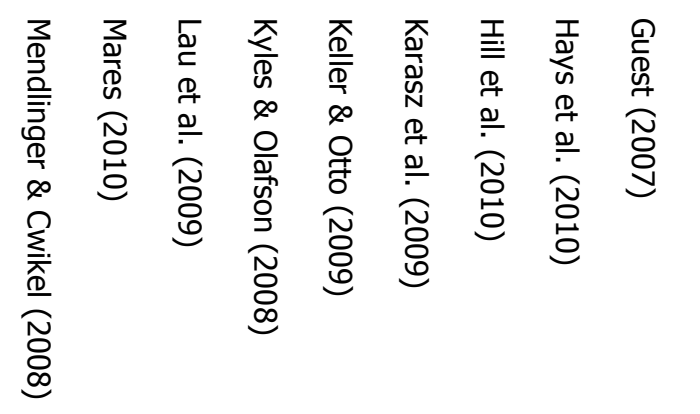

总

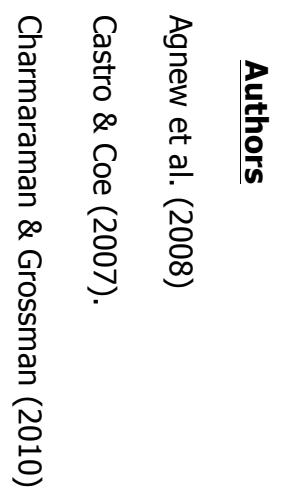

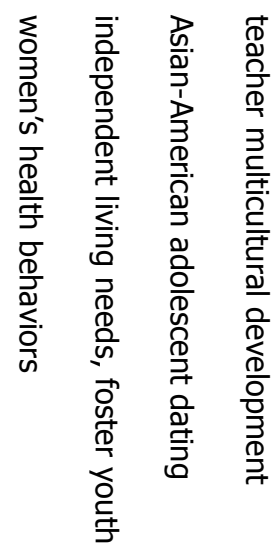

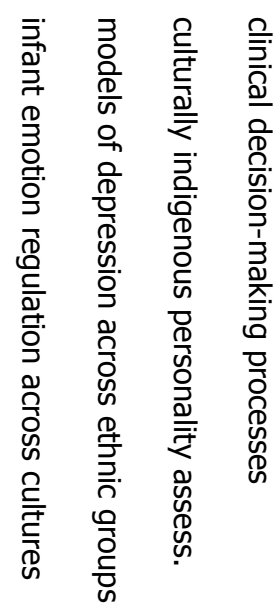

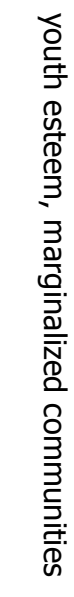

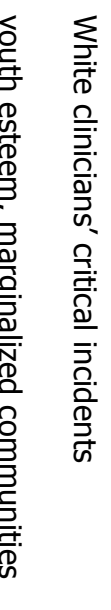

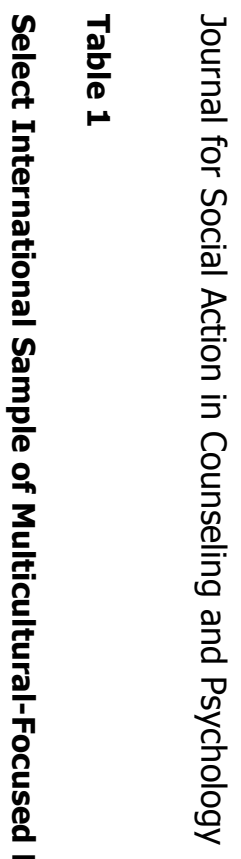

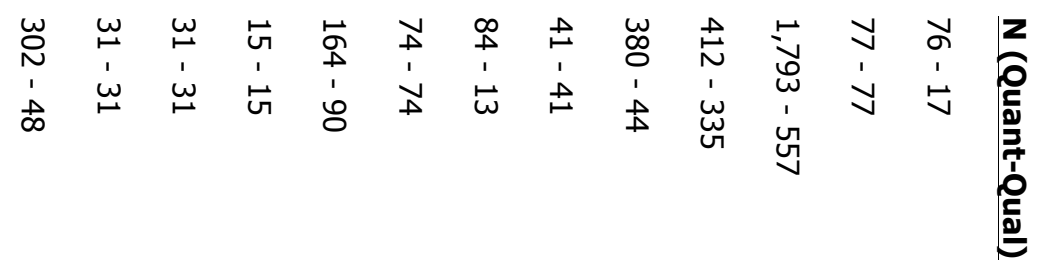

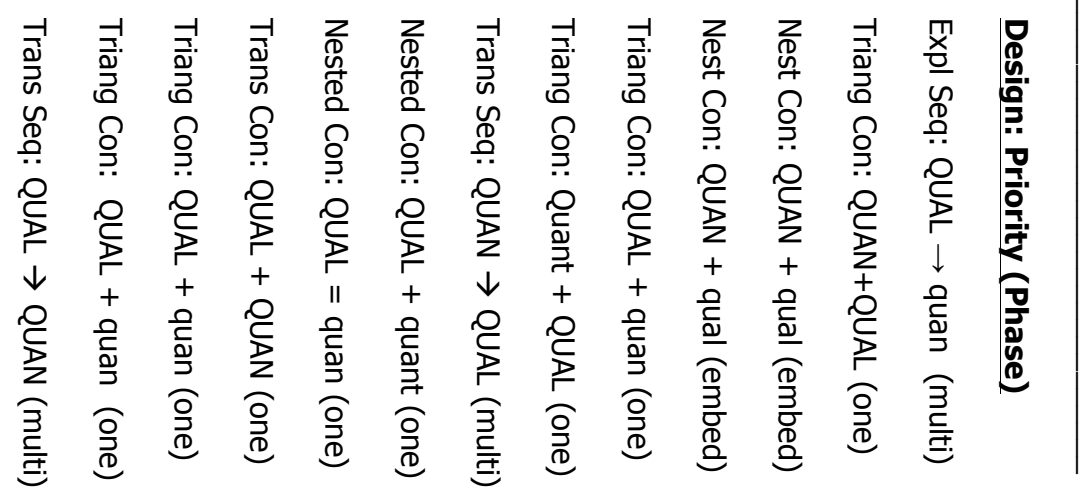




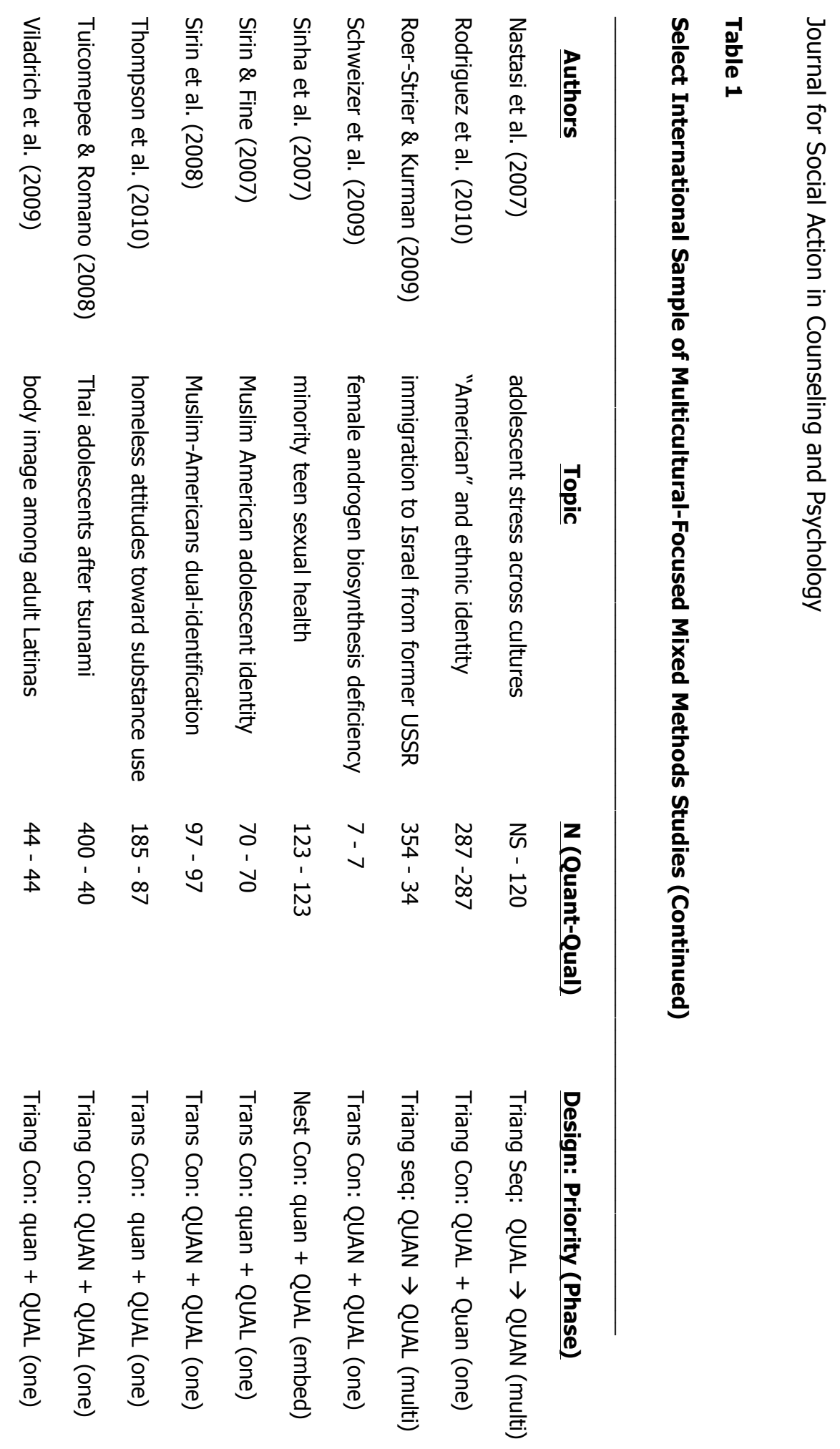

